\title{
BMJ Open Untangling the inter-relatedness within integrated care programmes for community-dwelling frail older people: a rapid realist review
}

\author{
Anam Ahmed (D) ,, ${ }^{1,2}$ Maria E T C van den Muijsenbergh (D) ,,3 Janne C Mewes, ${ }^{1}$ \\ Walter P Wodchis (D) , ${ }^{4,5}$ Hubertus J M Vrijhoef (1D) ${ }^{1,6}$
}

To cite: Ahmed A, van den Muijsenbergh METC, Mewes JC, et al. Untangling the inter-relatedness within integrated care programmes for community-dwelling frail older people: a rapid realist review. BMJ Open 2021;11:e043280. doi:10.1136/ bmjopen-2020-043280

- Prepublication history and additional supplemental material for this paper are available online. To view these files, please visit the journal online (http://dx.doi.org/10.1136/ bmjopen-2017-018426).

Received 31 July 2020 Revised 11 March 2021 Accepted 18 March 2021
Check for updates

(C) Author(s) (or their employer(s)) 2021. Re-use permitted under CC BY-NC. No commercial re-use. See rights and permissions. Published by BMJ.

For numbered affiliations see end of article.

Correspondence to

Anam Ahmed;

anam.ahmed@panaxea.eu

\section{ABSTRACT}

Objective To identify the relationships between the context in which integrated care programmes (ICPs) for community-dwelling frail older people are applied, the mechanisms by which the programmes do (not) work and the outcomes resulting from this interaction by establishing a programme theory.

Design Rapid realist review.

Inclusion criteria Reviews and meta-analyses (January 2013-January 2019) and non-peer-reviewed literature (January 2013-December 2019) reporting on integrated care for community-dwelling frail older people $(\geq 60$ years).

Analysis Selection and appraisal of documents was based on relevance and rigour according to the Realist And Meta-narrative Evidence Syntheses: Evolving Standards criteria. Data on context, mechanisms, programme activities and outcomes were extracted. Factors were categorised into the five strategies of the WHO framework of integrated people-centred health services (IPCHS).

Results 27 papers were included. The following programme theory was developed: it is essential to establish multidisciplinary teams of competent healthcare providers (HCPs) providing person-centred care, closely working together and communicating effectively with other stakeholders. Older people and informal caregivers should be involved in the care process. Financial support, efficient use of information technology and organisational alignment are also essential. ICPs demonstrate positive effects on the functionality of older people, satisfaction of older people, informal caregivers and HCPs, and a delayed placement in a nursing home. Heterogeneous effects were found for hospital-related outcomes, quality of life, healthcare costs and use of healthcare services. The two most prevalent WHO-IPCHS strategies as part of ICPs are 'creating an enabling environment', followed by 'strengthening governance and accountability'.

Conclusion Currently, most ICPs do not address all WHO-IPCHS strategies. In order to optimise ICPs for frail older people the interaction between context items, mechanisms, programme activities and the outcomes should be taken into account from different perspectives (system, organisation, service delivery, HCP and patient).
Strengths and limitations of this study

- By making use of realist research methods, this study provides insight into the inter-relatedness of context, mechanisms, programme activities and outcomes of integrated care programmes for community-dwelling frail older people.

- Experts and patient organisations were involved to test and refine the programme theory.

- Within this rapid realist review (RRR), data on context, mechanisms, programme activities and outcomes may show overlap, which is often considered an interpretative challenge within realist research.

- A broad definition of frailty was adopted in this RRR due to a lack of consensus on the term in the international scientific literature.

\section{INTRODUCTION}

Most older people develop care needs in multiple domains (ie, physical, mental and social at some point), and require coordinated care by multiple disciplines. ${ }^{1-4}$ The framework of integrated people-centred health services (IPCHS) by the WHO describes the complex nature of care for those with multiple needs. The challenge is to manage and deliver 'health services, so that people receive a continuum of health promotion, disease prevention, diagnosis, treatment, diseasemanagement, rehabilitation and palliative care services, coordinated across the different levels and sites of care within and beyond the health sector, and according to their needs throughout the life course $^{, 5}$ (p 2).

Despite the existence of this international framework for the delivery of people-centred and integrated care (IC), European healthcare systems face several issues, such as a lack of coordination and interprofessional collaboration, poor person-centredness of care and insufficient resources and support. ${ }^{6}$ Existing reviews on the effectiveness of integrated care 
programmes (ICPs) for (frail) older people have shown heterogeneity in outcomes. ${ }^{7-11}$ Insights into when ICPs do (not) work, for whom, why and how are lacking, and the mechanisms (M) and the influence of contextual factors often remain underexposed. The heterogeneity in the effectiveness of ICPs thus far has only been explained to a limited extent. Therefore, a more detailed understanding of the inter-relatedness of all factors that influence the effectiveness of ICPs for community-dwelling frail older people is needed.

Realist research is a way to offer such an understanding, as it aims to reveal the inner mechanisms by which a complex intervention operates. ${ }^{12}$ In addition to outcomes $(\mathrm{O})$, this approach examines the internal components of a care programme, unlike the traditional 'black box' approach, which mainly focuses on the outcomes, rather than how these outcomes were achieved. Thus, when applying a realist approach the specific aspects of the context $(\mathrm{C})$ that influence the effect of a complex programme and the mechanisms that may create the change can be identified. ${ }^{13}{ }^{14}$ In this study, a rapid realist review (RRR) was conducted. The term 'rapid' refers to applying a realist approach within a relatively short time frame. ${ }^{15}$

\section{Initial programme theory}

The aim of realist research is to test and refine an initial programme theory (PT) (a hypothesised explanation of how a complex intervention or programme is expected to work) in order to determine how, when and for whom the intervention or programme will work in a particular setting. ${ }^{16}$ In this RRR, the initial PT was based on the WHO-IPCHS framework. When developing the WHO-IPCHS framework, the WHO obtained experience and evidence on different levels (global, regional and national) from three different types of country settings (low, middle and high-income countries), and countries facing special circumstances (eg, conflict). In the framework, the WHO proposes five interdependent strategies that need to be adopted for health service delivery to become more integrated and people centred. ${ }^{5}$ The five inter-connected strategies are:

1. Engaging and empowering people and communities.

2. Strengthening governance and accountability.

3. Reorienting the model of care (ie, ensuring that efficient and effective healthcare services are designed, purchased and provided through innovative models of care).

4. Coordinating services within and across sectors.

5. Creating an enabling environment (ie, in order for the four previous strategies to become an operational reality, it is necessary to create an enabling environment that brings together all stakeholders to undertake transformational change).

In online supplemental file 1 , a summary and explanation of the strategies of the WHO-IPCHS framework is provided.

\section{Objectives}

An RRR was performed with the objective of gaining insight into the relationships between the context in which ICPs for community-dwelling frail older people are applied, the mechanisms by which the programmes do (not) work and the outcomes resulting from this interaction by establishing a PT on the effectiveness of IC for frail older people. Based on the WHO-IPCHS framework, this study also aims to explore to what extent the five strategies are applied in ICPs as reported in the literature.

\section{METHODS}

The methods were established prior to conducting the RRR and no deviations from the methods occurred.

\section{Rapid realist review}

An RRR was conducted to identify the mechanisms (enablers, underlying entities, processes, structures, reasoning, choices, collective beliefs) of ICPs that operate in particular contexts (wider external factors concerning implementation contexts, opportunities and resources to enact decisions, broad conditions and participant conditions) to generate outcomes (intended and unintended). ${ }^{16}$ This RRR was the first stage of a larger study in which insights of the literature will be assessed on their relevance in the Netherlands by a Delphi expert panel. For the larger study, a steering committee was established, consisting of experts in the field of IC for older people (for more details on the steering committee, see the Acknowledgements section). The involvement of experts working in the field is of great importance to realist research for providing input throughout the research process, as well as for being able to use the insights from the study to improve the quality of care in daily practice. ${ }^{17} 18$ The members of the committee provided feedback and guidance on the methods and the interpretation of the results. The steering committee was put in place by AA, METCM and HJMV and consisted of senior researchers in the field, a primary care practitioner and representatives of IC organisations.

\section{Search strategy}

Searches were conducted in PubMed, EMBASE, CINAHL, Web of Science and the Cochrane Library. All types of reviews (narrative, rapid, realist, scoping or systematic) and meta-analyses on ICPs for (frail) older people were included. ${ }^{19}$ In this review, an overarching/non-specific definition of frailty was adopted in order to include various populations of frail older people. This implies that studies reporting on frailty were included, without operationalising a new definition of frailty in this study. English or Dutch papers published between January 2013 and January 2019 were included. As IC for (frail) older people has changed rapidly in recent years, programmes from before 2013 were not considered relevant. Programmes included patients who were frail older people with a minimum age of 60 years, corresponding to the WHO 
definition of an 'older adult'. ${ }^{20}$ Programmes needed to describe ICPs that consist of at least two of the five strategies of the WHO-IPCHS framework (online supplemental file 2) provide an overview of the search terms used. The search took place in January 2019. We also searched the reference lists of the eligible papers identified for the review. An additional search of non-peer-reviewed literature was conducted using Google to identify relevant context, mechanisms and outcomes data. The key search terms of publications were similar to the ones of the peerreviewed literature search. Non-peer-reviewed literature published between January 2013 and December 2019 was included. Due to time constraints, and to capture the most relevant hits and ensuring a feasible quantity to screen, the first 10 pages (representing a total of 100 'best match' results) were examined. The non-peer-reviewed literature search took place in December 2019.

\section{Selection and appraisal of documents}

The titles and abstracts were screened by one author (AA) and supervised by a second author (HJMV). In case of even a slight doubt on selecting an article, the screener presented the article to the supervisor to ensure that articles were not overlooked or not included incorrectly. During full-text screening, the selection and appraisal of the papers was conducted by two authors (AA and JCM) based on their relevance (contribution to the development of the PT) and on their rigour (credible and trustworthy methods to generate data) in line with the Realist And Meta-narrative Evidence Syntheses: Evolving Standards quality standards. ${ }^{21}$ Disagreements were resolved by discussion resulting in consensus.

\section{Data extraction and analysis}

Data on context items, mechanisms, programme activities (PA) and outcomes were extracted and analysed. Per source publication, context-mechanism-outcome configuration $(\mathrm{s})(\mathrm{CMOc}(\mathrm{s}))$ were aimed to be identified. In case this was not possible due to the lack of data, overall common patterns in terms of context, mechanisms and outcomes in the source material were set out. In this review, the term 'programme activities' was used instead of 'interventions', as the term 'intervention' could cause confusion in relation to the composite nature of ICPs. Data extraction was performed by two authors (AA and HJMV). Disagreements about the category the extracted data belonged to (context, mechanism, programme activities or outcome) were resolved by discussion. Each context item, mechanism, programme activity and outcome that were reported in at least four papers were included in the analysis. Given the international perspective of this study and the variety of context items, mechanisms, programme activities and outcomes, we chose four papers as the minimum, realising this number is arbitrary.

\section{Programme theory}

Based on the CMOcs the PT was refined, describing the underlying relationships between context, mechanisms, programme activities and outcomes. Subsequently, two authors (AA and HJMV) individually categorised the context items, mechanisms, programme activities and outcomes into one (or more) of the five strategies of the WHO-IPCHS framework. The extent to which the strategies of the WHO-IPCHS framework were applied in the design and implementation of ICPs for community-dwelling (frail) older people was analysed. Categorisation was based on whether the context items, mechanisms, programme activities and outcomes corresponded to the strategic approaches and potential policy options and interventions provided by the WHO-IPCHS framework. ${ }^{5}$ Disagreements about which WHO-IPCHS strategy factors belonged to were resolved by discussion.

\section{Patient and public involvement}

This study was instigated by the National Health Care Institute, an advisory and implementing organisation who, among others, encourages good healthcare by helping all parties involved to continually improve healthcare quality and by helping patients find their way to high-quality care. A stakeholder dissemination meeting was held during the course of the study (April 2019). This meeting was held with the objective of sharing the results of the RRR and to consider stakeholder perspectives to test and refine the initial PT derived from the RRR. Among others, (representatives of) patient organisations attended this meeting.

\section{RESULTS}

A total of 374 papers were identified. After exclusion of the duplicates, 352 papers were screened on titles and abstracts. An additional 30 records were identified through a reference list search and added. After exclusion of 304 papers, the remaining 78 papers were screened on their full text. In this step, 51 papers were excluded (see figure 1 for more details). Finally, a total of 27 papers (15 papers from the peer-reviewed literature search and 12 papers from the non-peer-reviewed literature search) were included in the review (figure 1). The peer-reviewed papers included eight systematic reviews, ${ }^{9}{ }^{22-28}$ five nonsystematic reviews, ${ }^{29-33}$ one meta-analysis ${ }^{34}$ and one paper consisting of both a systematic review and meta-analysis. ${ }^{35}$ The non-peer-reviewed papers included four (policy) reports, ${ }^{66-38}$ four guides (for practitioners), ${ }^{39-42}$ three websites/online articles ${ }^{43-45}$ and one journal article. ${ }^{46}$ In online supplemental file 3 , an overview of the included papers is provided.

\section{Patient populations}

The patients included in the papers had chronic diseases or multimorbidity $(\mathrm{n}=8),{ }^{22} 242527-3034$ heart conditions $(\mathrm{n}=7)^{22-25} 293234$ or dementia $(\mathrm{n}=3) .{ }^{23} 2528$ Papers often did not specify exclusion criteria $(n=11) .^{22-24} 2629-35$ 


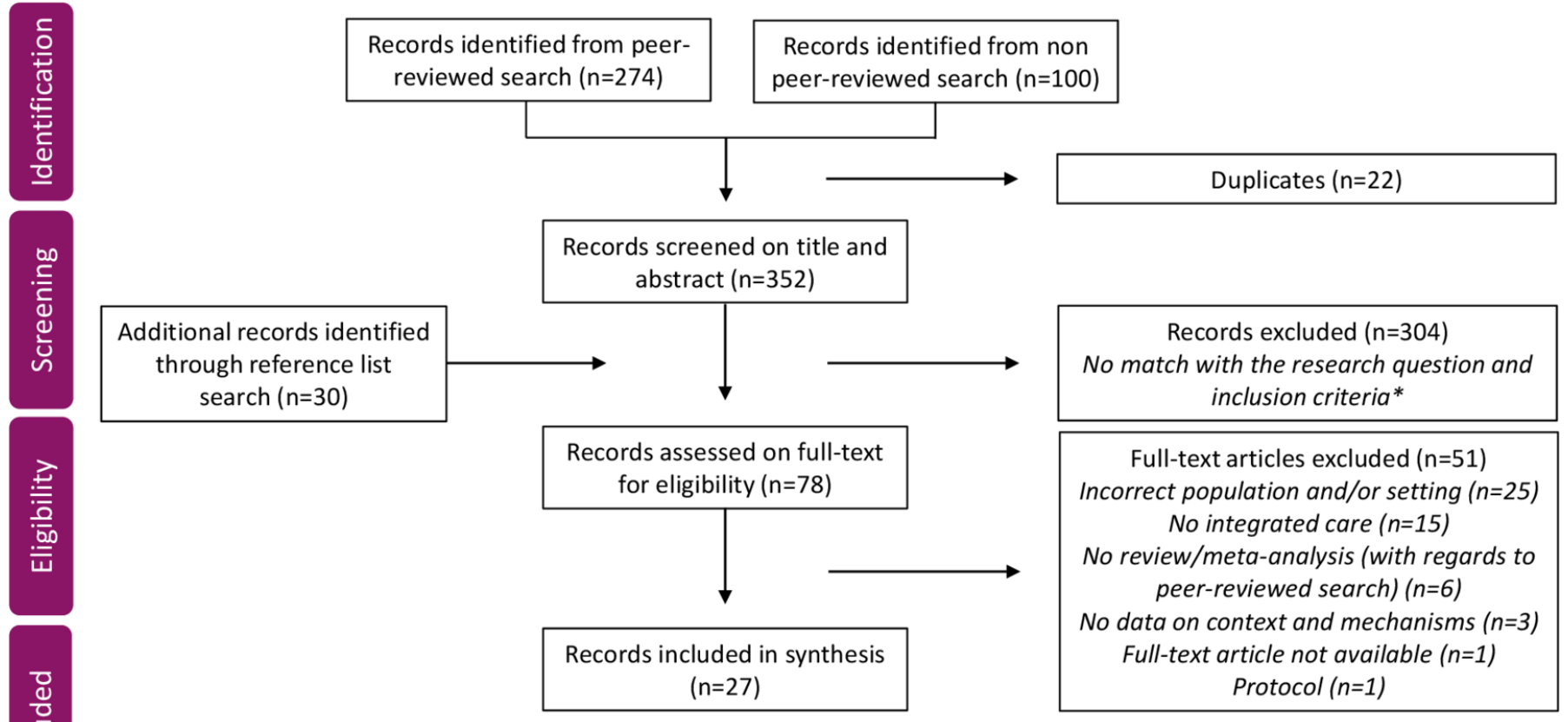

* Studies focus on irrelevant interventions, instruments, pharmaceuticals, disease-specific approaches, populations and/or settings or a combination of the aforementioned.

Figure 1 Flowchart of paper selection.

\section{Programme theory}

In table 1, the context items, mechanisms, programme activities and outcomes reported in the literature and their explanation are shown in ascending order of how often they were reported. Based on the identified factors, CMOcs were established (figure 2). In figure 2, each set of coloured arrows represents a CMOc, which indicate that mechanisms of action get triggered within a specific context and that these mechanisms lead to particular outcomes. The dashed arrows indicate incomplete configurations, where either a context factor is linked with a mechanism or an outcome, or a mechanism with an outcome. Findings in the form of CMOcs are described in the following PT for effective IC for older people.

Based on the needs of older people, the focus of IC should be on treating older people as individuals rather than a collection of diseases (M). In order to realise an appropriate approach and a successful use of risk prevention programmes, it is essential that the right patient population is identified and selected, for example, by use of a risk stratification tool (PA). Treatment approaches need to match the broad health issues/illness processes of frail older people by focusing on all life domains (ie, physical, mental and social), instead of single diseaserelated aspects (M) in order to achieve desired results, such as an improved quality of life of older people $(\mathrm{O})$.

Health education and training $(\mathrm{C})$ for older people and their informal caregivers could stimulate their active involvement in the care process $(\mathrm{M})$, leading to the patient and the healthcare providers(HCPs) understanding each other better, as well as the patient having more insight into the importance of his/her treatment
(M). Their involvement is important in setting up tailormade individual care plans (PA), leading to an improvement in functionality of the older person $(\mathrm{O})$, but also for managing medication treatment (PA), and planning follow-up support (eg, after hospital discharge) (PA) in order to have a reduced hospital (re)admission rate $(\mathrm{O})$.

To provide care in line with the vision of IC, it is essential to work with multidisciplinary core teams $(\mathrm{C}, \mathrm{M})$. These teams should consist of HCPs of various disciplines each having their own expertise (and include, for example, a case manager, a general practitioner, a geriatrician and an advanced nurse practitioner) (C) to meet the complex and diverse care needs of older people $(\mathrm{O})$. Team members need to have clearly defined roles and responsibilities and need to be aware of each other's expertise $(\mathrm{C})$ to work closely together effectively $(\mathrm{M})$ and to establish a well-working collaboration $(\mathrm{M})$, leading to higher satisfaction of older people, informal caregivers and HCPs $(\mathrm{O})$.

Training and education of HCPs in, for example, shared decision-making, patient empowerment, interprofessional collaboration and communication (C) needs to be an integral part of the healthcare system, as it is beneficial to enhance their skills and knowledge $(\mathrm{C})$ to improve the quality of healthcare $(\mathrm{O})$. With the help of training $(\mathrm{C})$ and by means of customised communication (M), PAs such as having (preventive) home visits (PA) and performing extensive geriatric assessments (PA) can be conducted in a more competently matter resulting in a delay in nursing home placement $(\mathrm{O})$ and a reduced use of healthcare services $(\mathrm{O})$. However, it is important that organisational alignment $(\mathrm{C})$ on all levels and the 

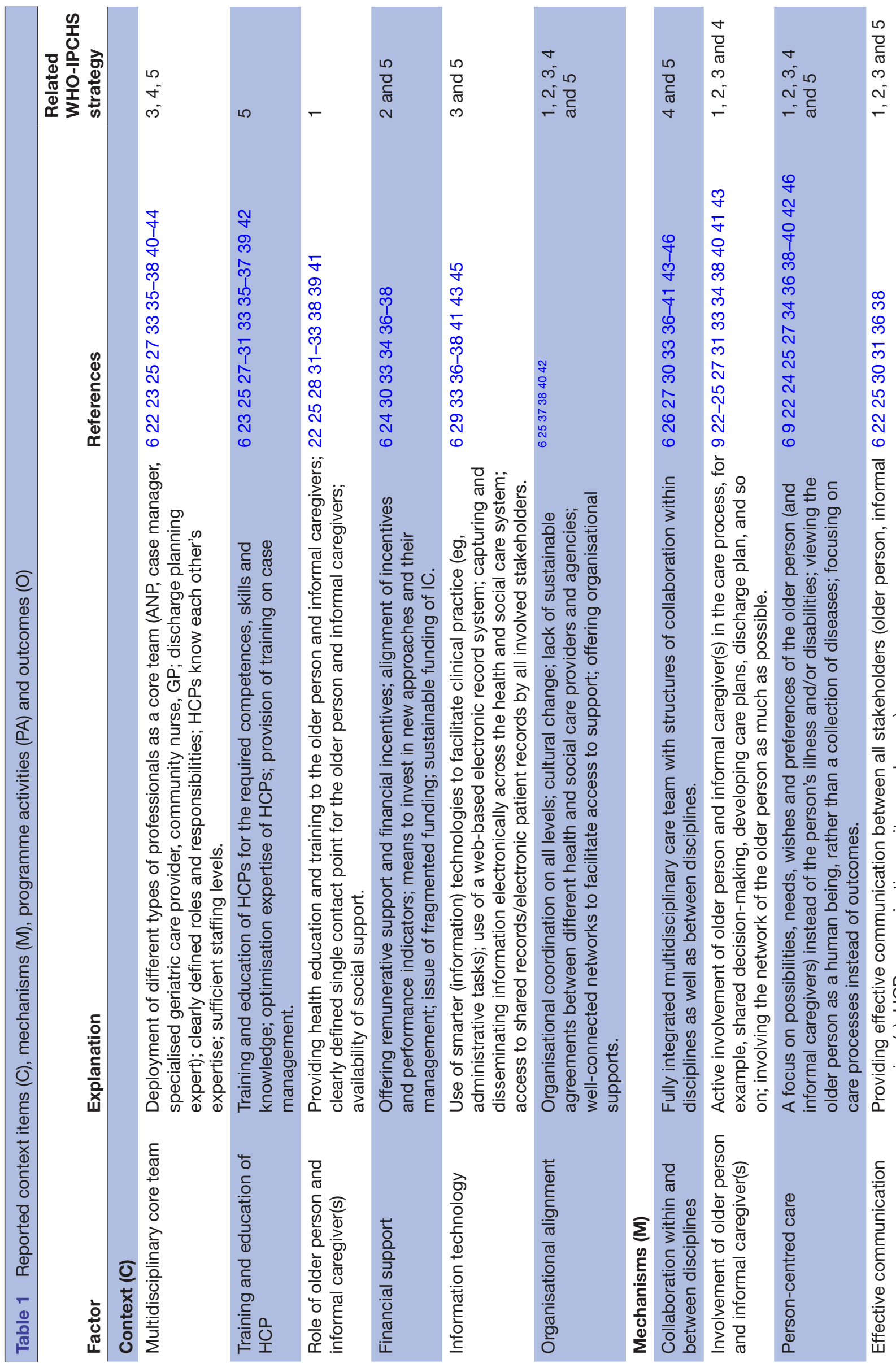

용

忿

듬

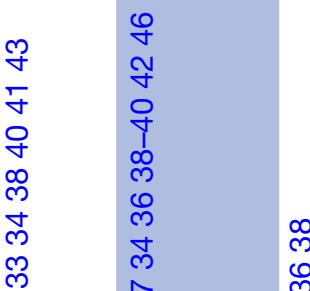

बิ

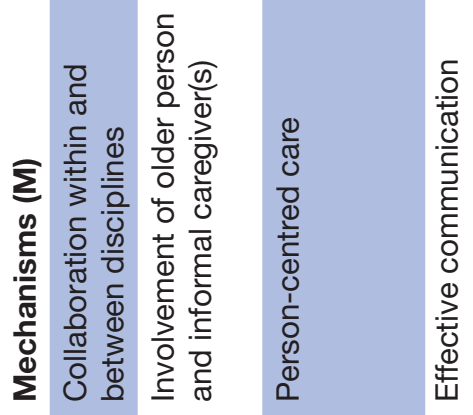




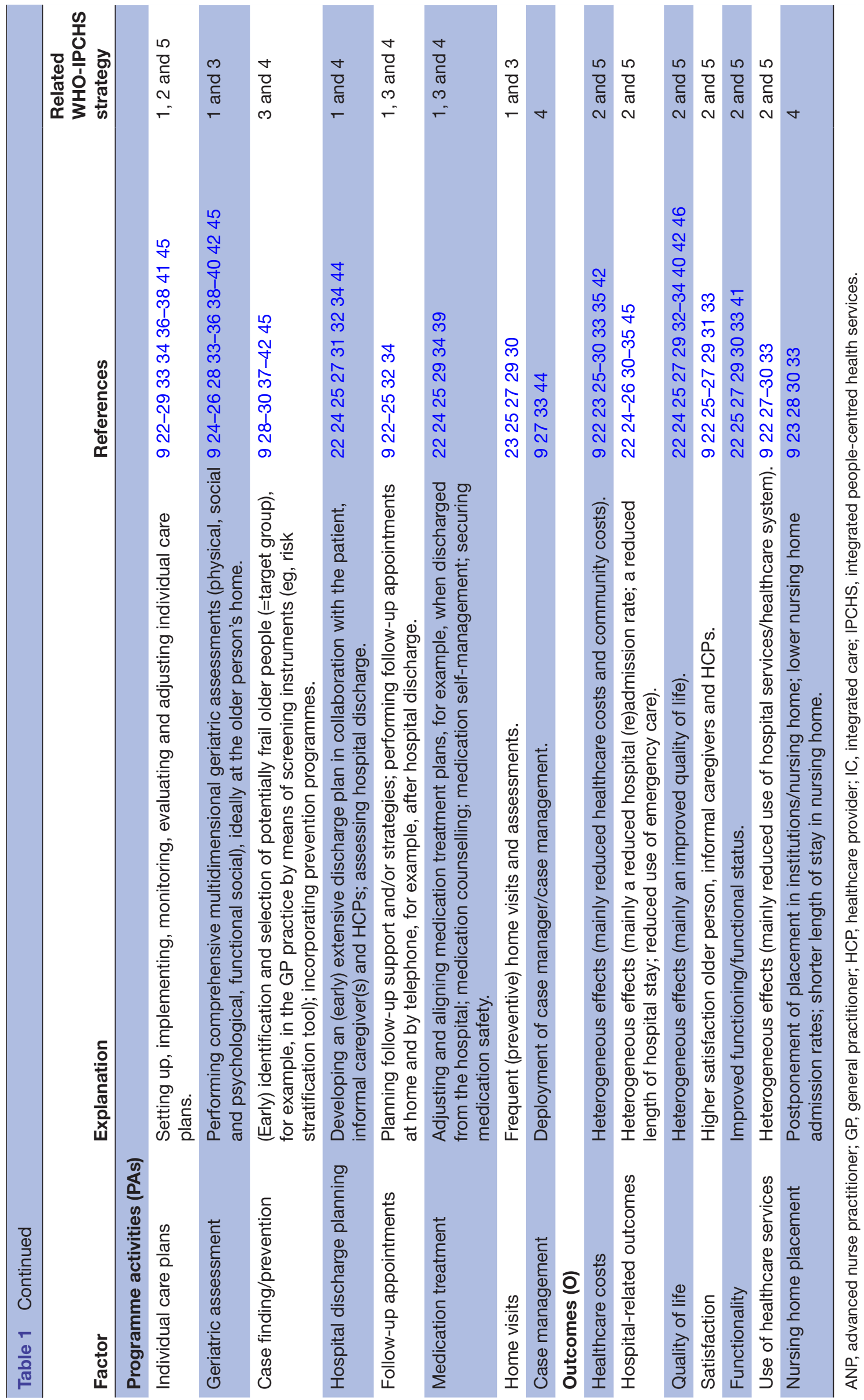

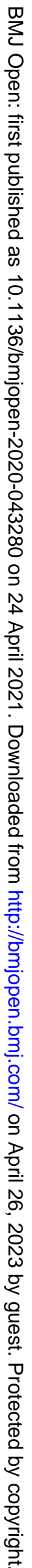




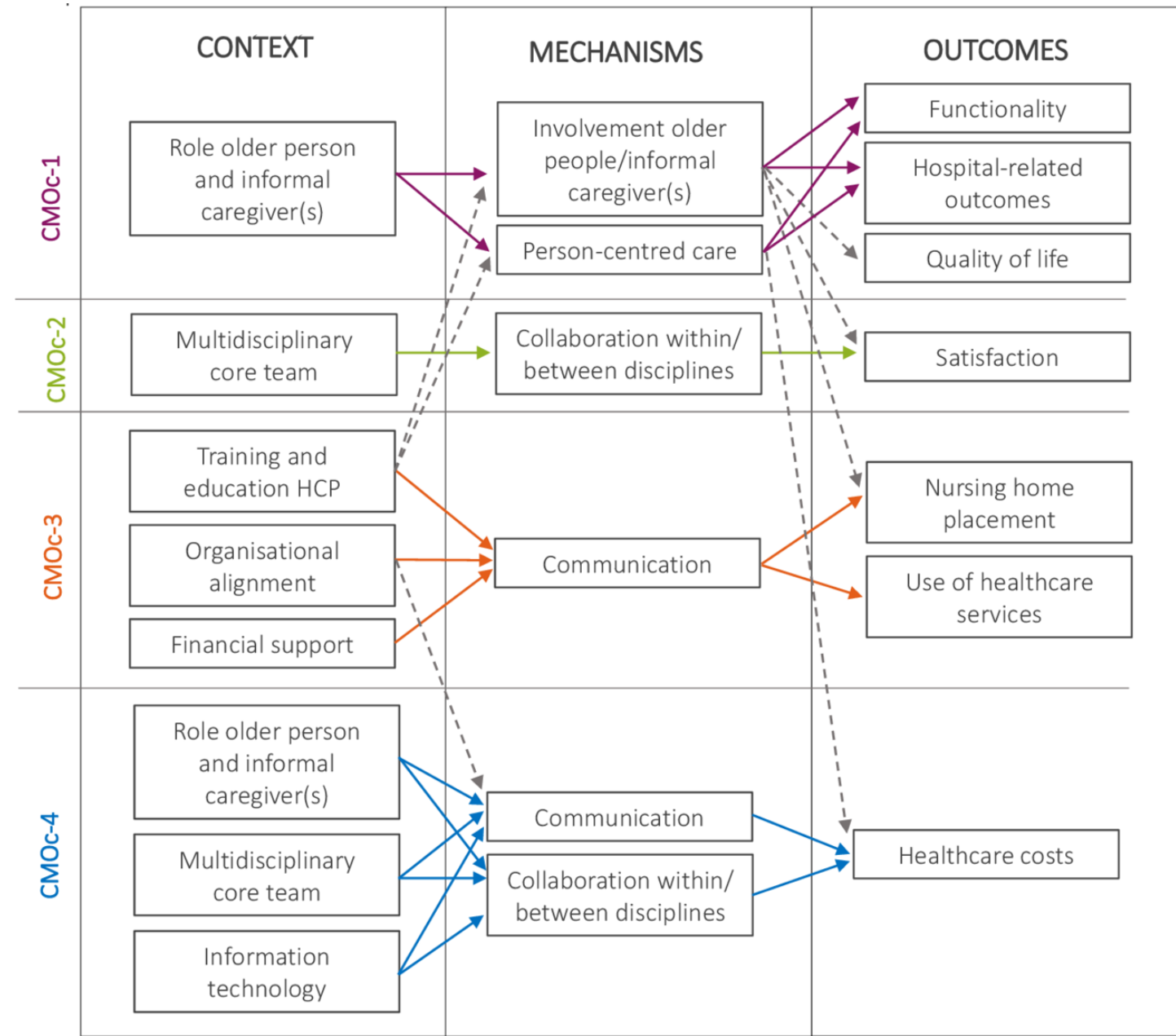

Figure 2 Context-mechanism-outcome configurations (CMOcs) of integrated care (IC) for community-dwelling frail older people. HCP: healthcare provider.

provision of sufficient financial resources $(\mathrm{C})$ is in place to realise the aforementioned activities.

Since frail older people are hospitalised relatively often, it is important that the core team includes an HCP (C) with expertise in hospital discharge planning (PA). This expertise entails developing an (early) extensive discharge plan (PA) in collaboration with the patient, informal caregiver(s) and HCPs $(\mathrm{C})$, as well as assessing hospital discharge (PA) and ensuring collaboration among all disciplines (M) involved in caring for the respective older person (PA). In the long term, it may entail reduced healthcare costs for the health system $(\mathrm{O})$. Information technology $(\mathrm{C})$ can support the collaboration, involvement and communication (M) of HCPs by enabling information sharing (PA) between, for example, professionals of different disciplines, older people and their informal caregivers (C); by enabling health-related social networks and patient-provider interactions; by supporting patient engagement; by providing electronic access to guidelines, protocols and other health information; and by sending reminders for providers and patients $(\mathrm{C})$.

\section{Link to the WHO-IPCHS framework}

In table 1 (rightmost column), the strategy/strategies of the WHO-IPCHS framework that relate to the extracted data are shown. These links with the WHOIPCHS framework demonstrated that the most prevalent strategy to which most of the context items, mechanisms, programme activities and outcomes are categorised into was strategy 5 'creating an enabling environment' (25\%), followed by WHO-IPCHS strategy 2 'strengthening governance and accountability' $(20 \%)$. Three WHO-IPCHS strategies were linked with context items, mechanisms, programme activities and outcomes to the same extent (all 18\%): 'engaging and empowering people and communities' (strategy 1), 'reorienting the model of care' (strategy 3) and 'coordinating services within and across sectors' (strategy 4).

Linking the items to the WHO-IPCHS strategies shows that regarding context items, WHO-IPCHS strategy 5 'creating an enabling environment' was most prevalent; regarding programme activities strategy 1 'engaging and empowering people and communities'; and regarding the outcomes both strategy 2 'strengthening governance and accountability' and strategy 5 'creating 
an enabling environment'. Concerning mechanisms, all strategies were equally prevalent.

\section{DISCUSSION}

In this RRR, we provided a detailed overview of the interrelatedness of context items, mechanisms, programme activities and outcomes of IC for community-dwelling frail older people. Further, we linked these factors to the strategies of the WHO-IPCHS framework to explore to what extent the strategies are applied in ICPs and refined the PT.

We developed a PT that explains how ICPs for community-dwelling frail older people work, for whom and why. The PT illustrated that it is essential to establish multidisciplinary teams of competent HCPs providing person-centred care, closely working together and communicating effectively with other stakeholders. Older people and informal caregivers should be involved in the care process in order to get a better picture of the patient's wishes and needs, and shared decision-making can be established. Financial support, efficient use of information technology and organisational alignment are also essential. ICPs demonstrate positive effects on the functionality of older people, satisfaction of older people, informal caregivers and HCPs, and a delayed placement in a nursing home. Heterogeneous effects were found for hospital-related outcomes, quality of life, healthcare costs and use of healthcare services. Outcomes of IC for frail older people are the result of interactions of context items, mechanisms and programme activities, as identified in this study. The interaction of factors can only partly explain the effects of IC, as the focus in evaluating outcomes primarily lies on PAs and outcomes compared with context and mechanisms.

Authors of papers included in this review reported that it was difficult to link ICPs to outcomes $(\mathrm{n}=9) .{ }^{9} 2223252728313235$ According to the authors, this was attributed to the differences in populations, variations in the content and characteristics of programmes and their activities and, generally, a lack of robust programmes. This, however, made it impossible, as part of this RRR, to shed light on why ICPs do not work.

The PT developed in this RRR should be considered a first step towards a more comprehensive PT. In this study, a linkage between the PT and the WHO-IPCHS framework shows that 'creating an enabling environment' (strategy 5) and 'strengthening governance and accountability' (strategy 2) seem to be prioritised in the way IC is currently delivered to older people, implicating that IC for older people still needs to be further developed, as not all five interconnected WHO-IPCHS strategies are equally prevalent in the current programmes. It must be noted that the WHO-IPCHS framework is transformative and given that healthcare systems are setting specific, its implications need to be aligned to the local context, values and preferences. In a follow-up study to this RRR, primary data on the relevance of the identified factors for the Dutch setting will be assessed. Context items, mechanisms, programme activities and outcomes reported in three papers or less, which are not included in the analysis of this study, will be included in the follow-up study.

The categories (context, mechanisms, programme activities, outcomes) factors belonged to sometimes differed in the included studies depending on the function they held within a programme, as reported by the papers. For example, the factor 'home visits' was reported as a programme activity by five papers, and as a context item by three papers. This accentuates the importance of accurately indicating the meaning of each factor within a programme. It also emphasises that when programmes are compared, the varied meanings of identical items may partly explain differences in outcomes between programmes with apparently similar factors.

Depending on the type of literature (peer reviewed vs non-peer reviewed), either the interpretive meaning of factors was described or a statement was given. For example, regarding the context item 'financial support', papers reported a lack of financial incentives and resources, and no sustainable funding being in place. ${ }^{631} 37$ Regarding the context item 'multidisciplinary core teams', papers mentioned constrained staffing levels, unclarity of roles and responsibilities of team members, and mutual unfamiliarity of professionals from different disciplines/ domains. ${ }^{6} 42$

Also, the theoretical underpinning of the interrelatedness of factors and the level factors are operating on are lacking in the literature. It was difficult to identify CMOcs per publication and their corresponding level, as very limited to no information on the interaction of factors was found per article. Consequently, the current PT may give an oversimplified impression of the interplay of factors. Evaluating ICPs is considered challenging due to their complex nature. ${ }^{47}$

\section{Comparison with other literature}

In line with this study, previous research demonstrated that the several components of ICPs for older people play a prominent role. However, the interaction of factors is underexposed as only one of the papers is a realist review, ${ }^{10}$ next to a scoping review, ${ }^{7}$ narrative review $^{48}$ and review of reviews, ${ }^{8}$ which mainly assessed components that contribute to IC. Studies reported the following components that correspond to the context items, mechanisms, PAs and outcomes found in this study: professional training of $\mathrm{HCPs}^{7810}$; incentives for integration and a funding system for $\mathrm{IC}^{710}$; patient education $^{8}$; organisational integration ${ }^{7}$; effective communication ${ }^{7} 10$; person-centred care $^{7}$; comprehensive/ geriatric assessment ${ }^{8}{ }^{48}$; case management ${ }^{78}{ }^{48}$; home visits $^{8}$; medication review ${ }^{8}$; developing care plans ${ }^{10}$; and discharge planning. ${ }^{7}$ Favourable effects regarding care utilisation (reduced) and health outcomes (improved) were found,,$^{10}{ }^{48}$ and mixed results on costs. ${ }^{48}$ Similarly, the review of reviews by Briggs $e t a l .^{8}$ also demonstrated that the focus of key elements of IC models for older 
people aligns with the WHO-IPCHS strategy 'creating an enabling environment' (strategy 5 ). ${ }^{8}$

\section{Strengths and limitations}

To the best of our knowledge, this is the first RRR that provides an overview of the interaction of context items, mechanisms, programme activities and outcomes and aligns them with the WHO-IPCHS strategies in order to explore to what extent the five strategies are applied in programmes. The strength of the realist approach lies in opening the black box, which leads to theory development explaining why ICPs (do not) work, for whom and under what circumstances. People from other countries may consider these findings useful to influence the effectiveness of ICPs for frail older people. Moreover, they are provided an overview of which WHO-IPCHS strategies are applied and which strategies are underexposed and deserve more attention. Another strength is the involvement of experts and (representatives of) patient organisations to test and refine the PT and to confirm findings.

A limitation to be considered is the definitions of context, mechanisms, programme activities and outcomes. Within the realist approach this is often a challenge, as there may be some overlap, since an outcome from one ICP may be a contextual factor in another. However, in this study, disagreement about the category data belonged to was resolved by discussion between the authors. A second limitation was the use of an overarching/non-specific definition of frailty due to a lack of consensus on the term in international scientific literature, resulting in a broad patient population. Even though definitions of frailty and multiple instruments to measure frailty are available, these are rarely reported in research concerning IC for frail older people. ${ }^{4-55}$ Four papers included in this study mentioned the heterogeneity in the patient population as a striking finding. ${ }^{962735}$

\section{Recommendations}

As the identified factors of ICPs for frail older people could not be aligned with all WHO-IPCHS strategies, ICPs need to have a more balanced application of all WHO-IPCHS strategies, as the realisation of all strategies in programmes ensures that health service delivery will be more people centred and integrated. Strategies most commonly reflected in ICPs are more administrative and planning focused, and less focused on the strategies that are related to actions associated with implementing new care models. In case one or more strategies are underexposed, it will affect progress in other strategies. ${ }^{5}$ To ensure that ICPs fulfil all five strategies, the WHO suggests implementation guidance support tools ${ }^{56}$ Further research of ICPs should make use of the existing operationalisations of frailty to define clear and complete description of patient groups and their health problems. This would enable to offer tailor-made programme activities to the different degrees of frailty. Lastly, additional realist research is needed to establish a more comprehensive PT for IC for frail older people. As very limited to no information on the interaction of factors was found within each article, more focus on the theoretical underpinning of the inter-relatedness of factors in the literature is needed by considering CMOc(s) within each article. Further setting-specific validation of context items, mechanisms, programme activities and outcomes of IC for frail older people needs to take place by involving older people and informal caregivers in the design and development of ICPs. As IC is in full development and needs to be defined more precisely than hitherto, ${ }^{57}$ this the study can be considered a valuable starting point for testing CMOcs and to use the study results as management information for the further application of IC.

\section{CONCLUSION}

In this RRR, we developed a PT that explains how ICPs for community-dwelling frail older people work, for whom and why. This study shows that ICPs for frail older people are still in development, as most ICPs do not address all WHO-IPCHS strategies. In order to optimise ICPs for frail older people, the comprehensiveness of the WHO-IPCHS framework and the interaction between context items, mechanisms, programme activities and the outcomes should be taken into account from different perspectives (system, organisation, service delivery, HCP and patient). Additional realist research is needed to establish more comprehensive PTs for IC for community-dwelling frail older people.

\section{Author affiliations \\ ${ }^{1}$ Panaxea, Amsterdam, Netherlands \\ 2Primary and Community Care, Radboudumc, Nijmegen, Gelderland, Netherlands \\ ${ }^{3}$ Prevention and Care, Pharos, Utrecht, Netherlands \\ ${ }^{4}$ Institute of Health Policy, Management and Evaluation, University of Toronto, Toronto, Ontario, Canada \\ ${ }^{5}$ Institute for Better Health, Trillium Health Partners, Mississauga, Ontario, Canada ${ }^{6}$ Department of Patient and Care, Maastricht University Medical Centre+, Maastricht, Netherlands}

Acknowledgements Our gratitude goes out to the steering committee of this study: Dr Isabelle Fabbricotti (Erasmus School of Health Policy and Management, Erasmus University Rotterdam, Rotterdam, The Netherlands); Dr Robbert Gobbens (Faculty of Health, Sports and Social Work, Inholland University of Applied Sciences, Amsterdam, The Netherlands; Zonnehuisgroep Amstelland, Amstelveen, The Netherlands; Department of Primary and Interdisciplinary Care, Faculty of Medicine and Health Sciences, University of Antwerp, Antwerp, Belgium); Dr Nick Goodwin (Faculty of Health and Medicine, University of Newcastle, New South Wales, Australia); Dr Pim Valentijn (Integrated Care Evaluation, Essenburgh, Hierden, The Netherlands). We also thank the team of the National Health Care Institute (Diemen, The Netherlands) for their collaboration throughout the research: Marjolein de Booys, MSc; Carel Mastenbroek, MSc; Aster de Lange, RN; and Tjitske Vreugdenhil, MD.

Contributors AA: methods design, search strategy design, quality assessment, data acquisition, data extraction, data analysis, interpretation of data, design and writing of the manuscript. METCM: interpretation of data, regularly reviewing the work, providing feedback on manuscript, manuscript final approval. JCM: quality assessment, providing feedback on manuscript, manuscript final approval. WPW: interpretation of data, providing feedback on manuscript, manuscript final approval. HJMV: concept and design of overall study, quality assessment, data 
analysis, interpretation of data, regularly reviewing the work, providing feedback on manuscript, manuscript final approval.

Funding Panaxea received funding for the larger study on which this manuscript is based from the Dutch National Health Care Institute/Zorginstituut Nederland (grant number: 2018054142).

Disclaimer The funding party had no role in the study design; in the collection, analysis and interpretation of data; in the writing of the manuscript; and in the decision to submit the article for publication. The views expressed are those of the authors and not necessarily those of the National Health Care Institute.

Competing interests None declared.

Patient consent for publication Not required.

Provenance and peer review Not commissioned; externally peer reviewed.

Data availability statement Data are available upon reasonable request. Most of the data generated or analysed for this study are publicly available. Any additional information is available from the corresponding author upon request.

Supplemental material This content has been supplied by the author(s). It has not been vetted by BMJ Publishing Group Limited (BMJ) and may not have been peer-reviewed. Any opinions or recommendations discussed are solely those of the author(s) and are not endorsed by BMJ. BMJ disclaims all liability and responsibility arising from any reliance placed on the content. Where the content includes any translated material, BMJ does not warrant the accuracy and reliability of the translations (including but not limited to local regulations, clinical guidelines, terminology, drug names and drug dosages), and is not responsible for any error and/or omissions arising from translation and adaptation or otherwise.

Open access This is an open access article distributed in accordance with the Creative Commons Attribution Non Commercial (CC BY-NC 4.0) license, which permits others to distribute, remix, adapt, build upon this work non-commercially, and license their derivative works on different terms, provided the original work is properly cited, appropriate credit is given, any changes made indicated, and the use is non-commercial. See: http://creativecommons.org/licenses/by-nc/4.0/.

\section{ORCID iDs}

Anam Ahmed http://orcid.org/0000-0002-3452-262X

Maria E T C van den Muijsenbergh http://orcid.org/0000-0002-4994-4008

Walter P Wodchis http://orcid.org/0000-0003-2494-7031

Hubertus J M Vrijhoef http://orcid.org/0000-0002-5539-4671

\section{REFERENCES}

1 Bodenheimer T. Long-term care for frail elderly people--the On Lok model. N Engl J Med 1999;341:1324-8.

2 Johri M, Béland F, Bergman $\mathrm{H}$. International experiments in integrated care for the elderly: a synthesis of the evidence. Int $J$ Geriatr Psychiatry 2003;18:222-35.

3 Boult C, Pacala JT. Integrating healthcare for older populations. Am J Manag Care 1999;5:45-52.

4 Kane RL. Managed care as a vehicle for delivering more effective chronic care for older persons. J Am Geriatr Soc 1998;46:1034-9.

5 World Health Organization. Framework on integrated, people-centred health services, 2016. Available: http://apps.who.int/gb/ebwha/pdf files/WHA69/A69_39-en.pdf?ua=1\&ua=1 [Accessed 30th Apr 2020].

6 SUSTAIN consortium. Sustainable tailored integrated care for older people in Europe (SUSTAIN-project) - Lessons learned from improving integrated care in Europe. Bilthoven/Amsterdam/ Canterbury 2018.

7 Threapleton DE, Chung RY, Wong SYS, et al. Integrated care for older populations and its implementation facilitators and barriers: a rapid scoping review. Int J Qual Health Care 2017;29:327-34.

8 Briggs AM, Valentijn PP, Thiyagarajan JA, et al. Elements of integrated care approaches for older people: a review of reviews. BMJ Open 2018:8:1-13.

9 Looman WM, Huijsman R, Fabbricotti IN. The (cost-)effectiveness of preventive, integrated care for community-dwelling frail older people: A systematic review. Health Soc Care Community 2019;27:1-30.

10 Kirst M, Im J, Burns T, et al. What works in implementation of integrated care programs for older adults with complex needs? A realist review. Int J Qual Health Care 2017;29:612-24.

11 Baxter S, Johnson M, Chambers D, et al. Understanding new models of integrated care in developed countries: a systematic review. Health Serv Deliv Res 2018;6:1-132.
12 Salter KL, Kothari A. Using realist evaluation to open the black box of knowledge translation: a state-of-the-art review. Implement Sci 2014;9:115-29.

13 Berwick DM. The science of improvement. JAMA 2008;299:1182-4.

14 Maxwell JA, Mittapalli K. Realism as a stance for mixed methods research. In: Tashakkori A, Teddlie C, eds. Mixed methods in social and behavioral research. 2nd edn. London, England: Sage Publications, 2010

15 Pawson R, Tilley N. Realistic evaluation. London: SAGE, 1997.

16 Wong G, Westhorp G, Pawson R. Realist synthesis - RAMESES training materials. London: University of London, 2013.

17 Saul JE, Willis CD, Bitz J, et al. A time-responsive tool for informing policy making: rapid realist review. Implement Sci 2013;8:103.

18 Balasubramanian BA, Cohen DJ, Davis MM, et al. Learning evaluation: blending quality improvement and implementation research methods to study healthcare innovations. Implement Sci 2015;10:219.

19 Hartling L, Chisholm A, Thomson D, et al. A descriptive analysis of overviews of reviews published between 2000 and 2011. PLoS One 2012;7:e49667.

20 World Health Organization. Proposed working definition of an older person, 2019. Available: http://www.who.int/healthinfo/survey/ ageingdefnolder/en/index.html [Accessed 30th Apr 2020].

21 The RAMESES II Project. Quality standards for realist evaluation, 2017. Available: http://www.ramesesproject.org/media/RE_Quality Standards_for_evaluators_and_peer_reviewers.pdf [Accessed 30th Apr 2020].

22 Allen J, Hutchinson AM, Brown R, et al. Quality care outcomes following transitional care interventions for older people from hospital to home: a systematic review. BMC Health Serv Res 2014;14:346.

23 Berthelsen CB, Kristensson J. The content, dissemination and effects of case management interventions for informal caregivers of older adults: a systematic review. Int J Nurs Stud 2015;52:988-1002.

24 Mabire C, Dwyer A, Garnier A, et al. Effectiveness of nursing discharge planning interventions on health-related outcomes in discharged elderly inpatients: a systematic review. JBI Database System Rev Implement Rep 2016;14:217-60.

25 Morilla-Herrera JC, Garcia-Mayor S, Martín-Santos FJ, et al. A systematic review of the effectiveness and roles of advanced practice nursing in older people. Int J Nurs Stud 2016;53:290-307.

26 Stall N, Nowaczynski M, Sinha SK. Systematic review of outcomes from home-based primary care programs for Homebound older adults. J Am Geriatr Soc 2014;62:2243-51.

27 Trivedi D, Goodman C, Gage H, et al. The effectiveness of interprofessional working for older people living in the community: a systematic review. Health Soc Care Community 2013;21:113-28.

28 You EC, Dunt DR, Doyle C. Case managed community aged care: what is the evidence for effects on service use and costs? J Aging Health 2013;25:1204-42.

29 Costa-de Lima K, Peixoto-Veras R, Pereira-Caldas C, et al. Effectiveness of intervention programs in primary care for the robust elderly. Salud Publica Mex 2015;57:265-74.

30 Frank C, Wilson CR. Models of primary care for frail patients. Can Fam Physician 2015;61:601-6.

31 Hudson R, Comer L, Whichello R. Transitions in a wicked environment. J Nurs Manag 2014;22:201-10.

$32 \mathrm{Kim} \mathrm{H}$, Thyer BA. Does transitional care prevent older adults from rehospitalization? A review. J Evid Inf Soc Work 2015;12:261-71.

33 Veras RP, Caldas CP, Motta LB. Integration and continuity of care in health care network models for frail older adults. Rev Saude Publica 2014;48:1-8.

34 Mabire C, Dwyer A, Garnier A, et al. Meta-Analysis of the effectiveness of nursing discharge planning interventions for older inpatients discharged home. J Adv Nurs 2018;74:788-99.

35 Huntley AL, Thomas R, Mann M, et al. Is case management effective in reducing the risk of unplanned hospital admissions for older people? A systematic review and meta-analysis. Fam Pract 2013;30:266-75

36 Baker M, Oliver D, Burns E. Integrated care for older people with frailty - innovative approaches in practice. London: Royal College of Practitioners and British Geriatrics Society, 2016.

37 Zorginstituut Nederland (ZIN). Startnotitie - Naar reguliere integrale zorg voor kwetsbare ouderen thuis kwetsbare ouderen thuis. Amsterdam 2018.

38 Wodchis WP, Dixon A, Anderson GM, et al. Integrating care for older people with complex needs: key insights and lessons from a sevencountry cross-case analysis. Int J Integr Care 2015;15:e021.

39 Dijk M, Mak S. Handreiking voor huisartsenpraktijken - betere zorg voor thuiswonende Amsterdamse ouderen, 2018. Available: https:// www.sigra.nl/sites/default/files/documents/boa_handreiking_voor huisartsenpraktijken_0.pdf [Accessed 30th Apr 2020]. 
40 Wind A, te Velde B. Kwetsbare ouderen thuis - handreiking voor integrale zorg en ondersteuning in de wijk, 2019. Available: https:// www.beteroud.nl/beteroud/media/documents/handreikingkwetsbare-ouderen-thuis-mei-2019_2.pdf [Accessed 30th Apr 2020].

41 Handboek Om U 3.0 Proactieve Integrale Ouderenzorg, 2018 Available: https://www.beteroud.nl/beteroud/media/documents/ Handboek-ouderenzorg-2018-V20180717.pdf [Accessed 30th Apr 2020].

42 NHS England. Safe, compassionate care for frail older people using an integrated care pathway: practical guidance for commissioners, providers and nursing, medical and allied health professional leaders. London, 2014.

43 Embrace. About embrace, 2017. Available: https://www.samenoud $\mathrm{nl} /$ over-samenoud/english-information/ [Accessed 30th Apr 2020].

44 Movisie. Integrale ouderenzorg gebaat bij goede samenwerking professionals - 4 knelpunten die integrale ouderenzorg bemoeilijken, 2019. Available: https://www.movisie.nl/artikel/integraleouderenzorg-gebaat-goede-samenwerking-professionals [Accessed 30th Apr 2020]

45 Sayer C. Improve frail elderly care with evidence, not intuition, 2014. Available: https://www.hsj.co.uk/commissioning/improve-frailelderly-care-with-evidence-not-intuition/5070273.article [Accessed 30th Apr 2020].

46 Verlee E, Van der Sande R, Abel R. Landelijke Eerstelijns Samenwerkings Afspraak Zorg voor kwetsbare ouderen. Huisarts \& Wetenschap 2017;60:S1-12.

47 Kumpunen S, Edwards N, Georghiou T. Evaluating integrated care. why are evaluations not producting the results we expect. London, UK: Nuffiel Trust, 2019.
48 Marino M, de Belvis AG, Tanzariello M, et al. Effectiveness and costeffectiveness of integrated care models for elderly, complex patients: A narrative review. Don't we need a value-based approach? Int J Care Coord 2018;21:120-39.

49 Gobbens RJJ, van Assen MALM, Luijkx KG, et al. The Tilburg frailty indicator: psychometric properties. J Am Med Dir Assoc 2010;11:344-55

50 Strawbridge WJ, Shema SJ, Balfour JL, et al. Antecedents of frailty over three decades in an older cohort. J Gerontol B Psychol Sci Soc Sci 1998;53:S9-16.

51 Fried LP, Tangen CM, Walston J, et al. Frailty in older adults: evidence for a phenotype. J Gerontol A Biol Sci Med Sci 2001:56:M146-57.

52 Puts MTE, Lips P, Deeg DJH. Static and dynamic measures of frailty predicted decline in performance-based and self-reported physical functioning. J Clin Epidemiol 2005;58:1188-98.

53 Rolfson DB, Majumdar SR, Tsuyuki RT, et al. Validity and reliability of the Edmonton frail scale. Age Ageing 2006;35:526-9.

54 Schuurmans $\mathrm{H}$, Steverink N, Lindenberg S, et al. Old or frail: what tells us more? J Gerontol A Biol Sci Med Sci 2004;59:M962-5.

55 Jones DM, Song X, Rockwood K. Operationalizing a frailty index from a standardized comprehensive geriatric assessment. J Am Geriatr Soc 2004;52:1929-33.

56 World Health Organization. Implementation support guidance, products and tools, 2020. Available: https://www.who.int/serviced eliverysafety/areas/people-centred-care/advocacy-products/en/ [Accessed 30 Apr 2020].

57 Hughes G, Shaw SE, Greenhalgh T. Rethinking integrated care: a systematic hermeneutic review of the literature on integrated care strategies and concepts. Milbank Q 2020;98:446-92. 